\title{
Supplementary measurements in the Sofia Geodynamic Network. Significance for contemporary local and regional geodynamics
}

\section{Допьлнителни измервания в Софийската геодинамична мрежа. Значение за локалната и регионалната сьвременна геодинамика}

\author{
Nikolay Dimitrov ${ }^{1}$, Radoslav Nakov ${ }^{2}$ \\ Николай Димитров ${ }^{1}$ Радослав Наков ${ }^{2}$ \\ ${ }^{1}$ National Institute of Geophysics, Geodesy and Geography, Bulgarian Academy of Sciences, Acad. G. Bonchev str. bl. 3,
1113 Sofia; E-mail: ndimitrov@geophys.bas.bg
${ }^{2}$ Geological Institute “Strashimir Dimitrov”, Bulgarian Academy of Sciences, Acad. G. Bonchev str. bl. 24, 1113 Sofia;
E-mail: radnac@geology.bas.bg
}

Abstract. The supplementary results are in agreement with previously obtained data that show southern motion of the stations with increasing velocities from north to south. They supplement the network in areas with missing data, but provide also new more accurate data at a local level. The velocities are from about $1.5 \mathrm{~mm} / \mathrm{y}$ of the northernmost station to slightly over $3 \mathrm{~mm}$ in the southernmost station. They are significant for the interpretation of the present-day geodynamics and may be used as well as for the evaluation of the geological hazards.

Keywords: geodynamics, GNSS, recent crustal movements.

\section{Introduction}

The region around Sofia and southwest Bulgaria is characterized by a large number of fault structures, and the presence of tectonic and seismic activity, thus predetermines the development of dangerous geodynamic processes. GNSS technology allows the study of modern tectonics because it provides quantitative estimates of the recent crustal movements. The study of the crustal movements is a complex problem for which the analysis of geodetic data provides important information. The region is of particular interest due to its high population density and high concentration of industrial facilities and resources. Possible strong earthquakes and related hazardous processes such as landslides, and rockfalls may cause material damage and have a negative psychological effect on the population. The above shows the importance to monitor the study area and the need to obtain reliable geological and geodetic data for its current geodynamic activity.

\section{Geodynamic settings}

The present-day geodynamics of the area is defined by the neotectonic extensional processes in the South
Bulgarian Extensional Region (Burchfiel et al., 2000), part of the broad East Mediterranean-Balkan Extensional system. Presently, based on geological data the extension is in a general N-S direction which results in tectonic structures with general trend NWSE to E-W. These structures are clearly expressed morphologically and define the topography of the area - elevated mountains (horsts) and subsided lands (grabens). In the area of Sofia historically are known few stronger earthquakes with suggested magnitudes 5.5-7.0 (Yosifov et al., 2018). The last one, of magnitude Mw 5.6 occurred on May 22, 2012 to the NW of Sofia around Pernik town (Radulov et al., 2012) along a fault of NW-SE trend.

\section{Monitoring the geodynamics of the area of Central Western Bulgaria}

In aim to supplement the available data and to obtain new data on the active geodynamics of the region the Department of Geodesy of the National Institute of Geophysics, Geodesy and Geography at BAS continues to monitor the recent crustal movements by performing GNSS measurements over the 
points of Sofia geodynamic network, that covers Central Western Bulgaria. The network is designed for high-precision GNSS measurements, determination of coordinates and velocities of points, calculation of active strain in the area and long-term monitoring crustal movements. The first GNSS measurements of the Sofia Geodynamic Network were made in 1997. Full measurement of the entire network with processing and analysis of the results has so far been performed in two epochs 1997 and 2000 (Kotzev et al., 2001, 2006). Third comprehensive measurements of the network were performed and published in 2020 (Dimitrov, Nakov, 2020). In the summer of 2021 additional measurements of 3 points was performed in aim to condense and expand the network. These additional measurements were accomplished in areas with lower density of observations and less reliable results.

\section{GNSS measurements 2021, processing and analyzing of the results}

After the comprehensive measurement of the geodynamic network in 2020, a new campaign was performed in the summer of 2021. Three additional points were measured - BELM, SATO and LOZ2 (Fig. 1). Point BELM was measured previously in 1997 and 2020, point SATO was measured in 1996 and 2003. Because the original point LOZE was destroyed after the measurements in 2000, in 2021 we measured the duplicating point LOZ2, which was measured in 1997 but with shorter period of observation. In this reason the obtained result for velocity of this point has greater error, but still is reliable. The measurements are processed and analyzed with the GAMIT-GLOBK software (Herring et al., 2015, 2018). Estimation includes data from campaigns 1997, 2000, 2020 and 2021 years. The result is velocity vectors shown with an arrow that indicates the direction and speed of GNNS sites. All obtained horizontal velocities are relative to Eurasia (Fig. 1).

Station LOZ2 is located SE of Sofia in the locality of Lozen village, on the northern slope of Lozen Mountain. Tectonically the area is dominated by several fault of general NW-SE trend. These faults shape the southeast part of Sofia Graben and the northern slope of Lozen Mountain. The faults affect the Miocene to present-day sedimentary infilling of

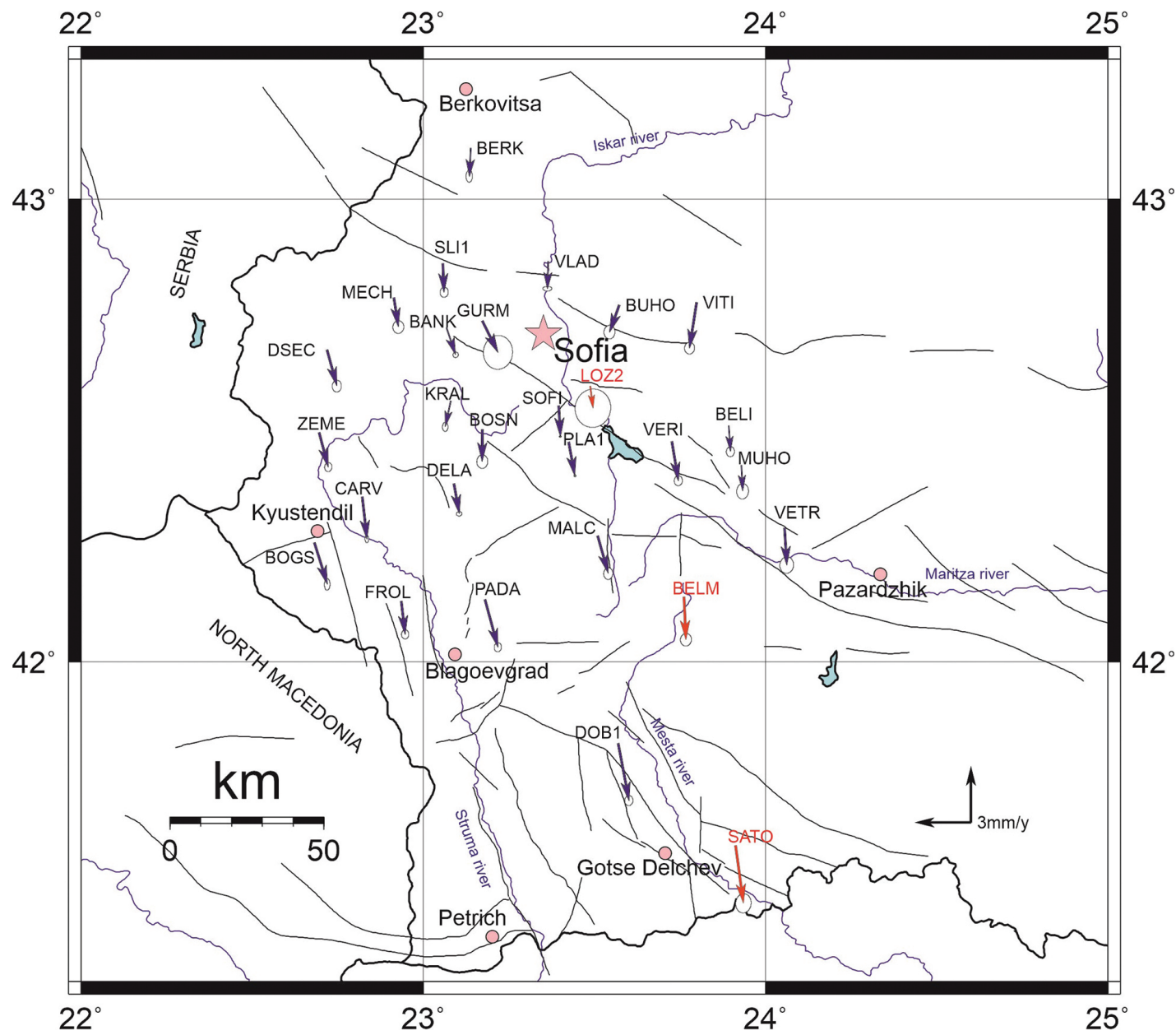

Fig. 1. Horizontal velocities relative to Eurasia with main faults, shown as slim lines. The newly observed stations are shown in red. 
the graben as well as basement rocks, forming the southern limiting fault of the graben. They are clearly geomorphologically expressed, forming a steplike relief toward the central part of Sofia graben. The obtained velocity for station LOZ2 is compatible to the surrounding points. However, its velocity is at the range of $1.5 \mathrm{~mm} / \mathrm{y}$ definitely slower compared to them. The velocity difference concerns especially western, eastern and southern lying stations GURM, VER, PLA1, SOFI. This result combined with the results of northern located stations BUHO and VITI suggests present-day tectonic activity in the Sofia graben and its bordering faults. The velocity differences suggest compression northern of LOZ2 and extension on the bordering faults to the south. Together with known active faults with NWSE trend, we have to suggest also the presence of faults obliquely to them, limiting areas of different velocities, creating a block structure. This is most probable for the space between stations LOZ2 and VERI. Such an active fault structure could be related to the S-N trending Iskar valley.

The station BELM is located in the northern slope of the elevated Rila Mountain. It has a very important location as it covers a broad region deprived of measurement, southern of Sofia region. It is also located to the south of the Maritsa Fault Zone, where no measurements from this mountainous area are available. The results are compatible with the obtained results from western and northern (MALC, VETR, VERI) laying stations. The obtained velocity around $3 \mathrm{~mm} / \mathrm{y}$ confirms the increasing velocities of stations south of the Northern Rila (Dzherman) Fault and Maritsa Fault System (see Dimitrov, Nakov, 2020).

The station SATO is located in the bordering region with Greece, in the southern part of the West Rhodopes. It is providing results for an area with missing data. The obtained velocity is over $3 \mathrm{~mm} / \mathrm{y}$. It is compatible to the closest northern located station DOB1. Both results show an increasing velocity compared to northern located stations. Probably, the results suggest that the south westernmost part of Bulgaria encompassing Pirin and West Rhodopes Mountains behave as a homogeneous geodynamic area with sharply higher velocities compared to the northern region, however this suggestion needs more data in western and eastern direction.

\section{Conclusions}

The newly acquired velocities from three campaigns 1997, 2000 and 2020 years, complemented with the new results from 2021 confirm that the general tendency of movement of the stations in the region of
Central Western Bulgaria is in the south direction with respect to stable Eurasia. In a general way the velocities tend to increase from north to south. This pattern is in agreement with the extensive movement of Southern Bulgaria and Northern Greece. The new results provide much better accuracy, reliability and local details. The obtained results show, that the measurements may confirm previous results in area with missing data, but provide also new more accurate data at a local level. They are an important tool for the interpretation of the presentday geodynamics and may be used as well as for the evaluation of the geological hazards. Further extension of Sofia geodynamic network in its periphery will provide new details on the geodynamics of the area. A denser network will be also very useful in and around Sofia graben.

Acknowledgements: This study was supported by National Science Fund, Bulgaria, Project " Monitoring of geodynamic processes in the area of Sofia”. Contract No КП-06-H 34/1.

\section{References}

Burchfiel, B. C., R. Nakov, Tz. Tzankov, L. H. Royden. 2000. Cenozoic extension in Bulgaria and Northern Greece: The northern part of the Aegean extensional regime. - In: Bozkurt, E., J. A. Winchester, J. D. A. Piper (Eds.). Tectonics and Magmatism in Turkey and the Surrounding Area. Geol. Soc., Sp. Publ., 173, 325-352; https://doi.org/10.1144/ GSL.SP.2000.173.01.16.

Dimitrov, N, R. Nakov. 2020. Recent GPS results on the geodynamics of the area around Sofia (Central-Western Bulgaria). - Rev. Bulg. Geol. Soc., 81, 3, 241-243.

Herring, T. A., M. A. Floyd, R. W. King, S. C. McClusky. 2015. GLOBK Reference Manual, Global Kalman Filter VLBI and GPS Analysis Program, Release 10.6. Cambridge, MA, Massachusetts Institute of Technology, $95 \mathrm{p}$.

Herring, T. A., R. W. King, M. A. Floyd, S. C. McClusky. 2018. GAMIT Reference Manual, GPS Analysis at MIT, Release 10.7. Cambridge, MA, Massachusetts Institute of Technology, $54 \mathrm{p}$.

Kotzev, V., R. Nakov, B. C. Burchfiel, R. W. King, N. Dimitrov. 2001. Active deformation in the Sofia region inferred from geodetic measurements - Proc. Final Confer. Intern. Project "Expert Assessment of Land Subsidence Related to Hydrogeological and Engineering Geological Conditions in the Regions of Sofia, Skopje and Tirana", June 27-30, 2001, Sofia, 99-102.

Kotzev, V., R. Nakov, Tz. Georgiev, B. C. Burchfiel, R.W. King. 2006. Crustal motion and strain accumulation in western Bulgaria. - Tectonophys., 413, 3-4, 27-145; https:// doi.org/10.1016/j.tecto.2005.10.040.

Radulov, A., M. Yaneva, S. Shanov, K. Kostov, V. Nikolov, N. Nikolov. 2012. Coseismic geological effects related to the May 22, 2012 Pernik earthquake, Western Bulgaria. - Proc. Nat. Conf. Bulg. Geol. Soc., Geosciences 2012, 121-122.

Yosifov, D., I. Paskaleva, E. Botev, B. Rangelov. 2018. The Seismic Risk for Sofia. Sofia, NTS MDGM, 207 p. (in Bulgarian). 